\title{
Dançando para a cidadania: reflexões sobre práticas artísticas e educativas desenvolvidas em uma ONG de Santa Maria - RS
}

\author{
Daniela Grieco Nascimento e Silva* \\ Silvia Susana Wolff ${ }^{* *}$
}

\begin{abstract}
Resumo
Este artigo objetiva verificar a influência do balé, tal como desenvolvido na ONG Royale, nos processos de inclusão social, construção e manutenção da cidadania de jovens da periferia da cidade de Santa Maria - RS. Para tal realizou-se uma investigação qualitativa, tendo como instrumentos de pesquisa o uso de entrevistas e observações. O processo artístico-educativo desenvolvido pela ONG Royale, que tem o balé como eixo central, propicia influências nas construções das identidades pessoais e coletivas, o que indica possibilidades do desenvolvimento da conscientização de seus papéis como cidadãs.

Palavras-chave: Balé; Educação; Cidadania.
\end{abstract}

\section{Dancing for the citizenship: reflections about educational and artistic practices developed by an NGO in Santa Maria - RS}

\begin{abstract}
The current study aims to verify the influence of ballet, as developed by the NGO Royale, in the processes of inclusion, citizenship construction and maintenance of young people from the periphery of Santa Maria- RS. This qualitative nature research is called Life History. Two fifteen-year-old girls from Royale were selected for this study. As research tools, open interviews and observation of actions have been used. The results emphasize that the practice of ballet, as it has been developed in the NGO has influenced positively the processes of social inclusion, citizenship construction and maintenance of young people from the mentioned area.
\end{abstract}

Keywords: Ballet; Education; Citizenship.

\section{Introdução}

Este trabalho tem por objetivo verificar a influência da arte do balé, tal como desenvolvido na ONG Royale Escola de Dança e Integração Social, nos processos de inclusão social, construção e manutenção da cidadania de jovens da periferia da zona oeste da cidade de Santa Maria - RS. Na investigação, denominada História de Vida, o método utilizado foi de pesquisa de cunho qualitativo. Para participar deste estudo foram escolhidas duas jovens com faixa etária entre $15 \mathrm{e}$ 16 anos, participantes das ações sociais da Royale há, no mínimo, quatro anos, pertencentes às famílias cujas rendas variam entre um a dois salários mínimos e moradoras de uma das oito comunidades atendidas pela referida $\mathrm{ONG}$.

Como instrumentos de pesquisa, foram utilizadas entrevistas abertas e observações das jovens em suas ações na Royale, sendo as categorias de análise constituídas por eixos temáticos. Deste modo, este trabalho foi estruturado em três momentos: o primeiro apresenta uma reflexão sobre a proposta artístico-educativa da ONG Royale Escola de Dança e Integração Social; o segundo descreve e pontua as contribuições do uso de entrevistas e observações na pesquisa aplicada ao campo da educação; o terceiro explora analiticamente as informações obtidas pelos recursos das entrevistas e das observações.

\section{Primeiro momento: reflexões sobre a proposta artístico-educativa da ONG Royale Escola de Dança e Integração Social.}

Em 1996, a Royale, ainda como instituição privada, iniciou uma oficina gratuita de balé para crianças pobres de uma escola da rede municipal de ensino. Este trabalho encontrou grande receptividade na comunidade e extrema dedicação por parte das crianças. Assim, a direção da Royale decidiu ampliá-lo. Em 1997, apresentou para a Prefeitura Municipal um projeto e então abriu 40 vagas para crianças das escolas da rede municipal. Essa experiência mudou totalmente o curso da finalidade da Royale. Auxiliada por um grupo de professores universitários da área da educação e com o apoio de alguns cidadãos, que compreenderam e acreditaram na nova proposta, a Royale Academia de Ballet transformou-se, em

\footnotetext{
*Endereço Eletrônico: daninasc@yahoo.com.br

***Endereço Eletrônico: silviawolff@bol.com.br
} 
06/06/1998, na Royale Escola de Dança e Integração Social, uma entidade civil sem fins lucrativos. Sua missão passou a ser não apenas a de ensinar balé, mas de tornar a arte e a educação agentes motivadoras no desenvolvimento integral das potencialidades e na inclusão social, cultural e educacional de crianças, adolescentes, portadores de deficiências e suas famílias expostas a situações de vulnerabilidade em oito comunidades periféricas da zona oeste da cidade de Santa Maria, estado do RS.

As demandas sociais das comunidades atendidas são inúmeras, destacando-se a falta de emprego, a desestruturação familiar, casos de dependência química, alcoolismo, violência doméstica, tráfico de drogas, gravidez precoce, prostituição infanto-juvenil e índice de $60 \%$ de evasão escolar.

Diariamente, no turno inverso ao das escolas regulares frequentadas pelas 200 alunas, são realizadas ações interdisciplinares que tem o balé como eixo temático central, de modo a integrar o conhecimento corporal ao conhecimento intelectual e à percepção de si mesmo.

Estas ações são divididas em cinco eixos -

Oficina Dança Cidadã, Oficina de Apoio Pedagógico, Oficina de Artes Visuais, Oficina de Língua Francesa, Apoio Psicológico -, propiciando espaços artísticos e educativos que levam ao autoconhecimento, à criação, à reflexão crítica e à participação democrática. Tais fatores fortalecem a autoestima, a autonomia e a socialização, como também elevam o nível de conhecimentos gerais que, sem dúvida, refletem-se no desempenho escolar e na idealização e construção de um futuro melhor para si e para sua comunidade.

A fim de combater o alto índice de evasão escolar, a Royale Escola de Dança e Integração Social trabalha em parceria com as escolas regulares da região oeste, realizando reuniões mensais com as coordenações pedagógicas de modo a acompanhar a frequência e o desempenho escolar de suas alunas. Este acompanhamento também é realizado através da análise dos boletins/pareceres emitidos pelas escolas. Quando é detectada alguma aluna com baixo rendimento escolar, a mesma é encaminhada para o reforço escolar ou atendimento psicopedagógico da Royale.

A fim de fortalecer o núcleo familiar e construir um vínculo maior da Royale com as comunidades atendidas, para as famílias são desenvolvidas palestras, seminários e grupos de orientação psicológica que possam auxiliá-las a redescobrir e a rediscutir o mundo que as cerca.
A Proposta Artístico-Educativa tem como base central os princípios teóricos de Paulo Freire (1977), procurando desenvolver uma educação problematizadora com base no diálogo e na reflexão crítica do entorno, utilizando os quatro pilares da educação propostos por Jacques Delors (1996): aprender a conhecer, a fazer, a viver com os outros e a ser. Baseia-se também na aquisição dos Códigos da Modernidade, propostos para a escola regular básica, apresentadas por Bernardo Toro (1997), que são: o domínio da leitura e da escrita; a capacidade de calcular e de resolver problemas; as condições de compreender e atuar em seu entorno social; a habilidade de escrever, interpretar e analisar fatos e situações; a capacidade de acessar informações; a capacidade de trabalhar em grupo.

A partir de tais princípios ocorre a construção do Tema Gerador do espetáculo de dança de final de ano letivo. O Tema Gerador é escolhido pelas educandas através de um processo eletivo direto e norteia as ações de todas as oficinas durante o ano letivo. Assim, no segundo semestre de cada ano são lançados, nas aulas da Oficina de Apoio Pedagógico, vários disparadores de possíveis temáticas geradoras, como notícias e artigos de jornais e revistas, poemas, contos, biografias de artistas, etc. As alunas escolhem os disparadores mais potentes, até que são escolhidas três temáticas principais. Estas são apresentadas para todas as turmas e fixadas no mural de notícias da Royale. Após um mês de contato e estudo das três temáticas principais, é realizada uma eleição direta e, então, escolhido o Tema Gerador do espetáculo do próximo ano.

Por meio deste processo é oportunizado que as educandas estudem criticamente o Tema Gerador e possam não apenas construir o espetáculo de dança, mas acima de tudo, refletir sobre si mesmas, sobre o mundo e sobre seu papel no mundo, fazendo com que o balé adentre nas problemáticas do mundo contemporâneo em um processo analítico que rompe as cadeias de simples repetições silenciosas e submissas de movimentos.

Sobre tal processo, Klauss Vianna (2005) coloca que:

Uma sala de aula não pode ser esse modelo que vemos, no qual a disciplina tem algo de militar, não se pergunta, não se questiona, não se discute, não se conversa. Com isso, a tradição do balé se perde em repetições de formas, em que todo o trabalho é feito aleatoriamente [...] A sala de aula, dessa forma, torna-se apenas uma arena para a competição de egos, onde ninguém se 
interessa por ninguém a não ser como parâmetro para a comparação [...] A dança não se faz apenas pensando, mas também pensando e sentindo: dançar é estar inteiro. Não posso ignorar minhas emoções em uma sala de aula, reprimir essas coisas todas que trago dentro de mim (VIANNA, 2005, p. 32).

Dentro desses pressupostos, o estudo do Tema Gerador constitui-se num universo temático que envolve todos os participantes: educadoras, alunas, famílias, comunidades. Constitui-se num processo de reflexão e construção constante das educadoras que, a partir das demandas das educandas e também das famílias, vão reelaborar suas propostas e suas ações artísticas e educativas.

Com dezoito anos de trabalho, a Royale já formou várias bailarinas que, ao concluir os nove anos de formação na técnica do balé, realizam estágio supervisionado de um ano como monitoras nas aulas de dança clássica. As professoras de balé que atuam na Royale estabeleceram um processo de formação, que estruturou um programa para as aulas de dança clássica baseado nos conhecimentos sistematizados pelas docentes durante a elaboração e execução de suas próprias aulas.

Este programa procura incentivar a percepção corporal, a percepção dos movimentos que o corpo executa, a fim de que as bailarinas possam compreender a mecânica dos movimentos e trabalhá-los de acordo com as suas anatomias e com suas marcas sociais e culturais, pois:

Quando se fala em técnicas corporais, deve-se sempre usar o plural, pois não existe somente um corpo, mas vários, subentendidos nas experiências e nas técnicas corporais particulares. O corpo tem uma forma, um sexo, uma massa ou um peso. Ele tem uma memória como registro de uma história passada - e, ao mesmo tempo, ele é uma projeção para o futuro, com sua bagagem genética, seus desejos, sonhos, projetos (STRAZZACAPPA, 2012, p. 31).

Assim, busca-se desenvolver o ensino de balé na Royale procurando ampliar a percepção corporal das bailarinas, de maneira que elas possam compreender a execução dos movimentos, respeitando as diversidades corporais. Sem focalizar apenas na apreensão técnica, mas principalmente na satisfação em dançar, na capacidade de expressar-se por meio do seu corpo.

Por ser compreendida como uma metodologia da práxis, a proposta artístico- educativa da Royale é construída de forma dialógica entre educadoras e educandas e gerida de acordo com suas próprias demandas. A problematização, ao objetivar a compreensão da realidade circundante, origina um conhecimento crítico, reflexivo, sensível e eternamente revisor de si mesmo, que propicia a inclusão e a transformação, levando a linguagem do balé ao encontro do mundo contemporâneo.

\section{Segundo momento: os caminhos metodológicos}

A fim de desenvolver este estudo, foi realizada uma pesquisa qualitativa do tipo estudo de caso denominada História de Vida, pois de acordo com Araújo e Santos (2007), objetiva investigar, registrar e analisar a experiência de vida de uma pessoa pertencente a um determinado grupo social.

Eliseu Clementino de Souza (2006) pontua que o relato propiciado pela História de Vida tem na utilização da entrevista e na análise de diários pessoais os seus principais instrumentos, pois ambos permitem compreender a vida do sujeito de acordo com o contexto histórico e social em que vive. As entrevistas, tanto semi-estruturadas quanto abertas, constituem-se numa maneira de investigação sobre o modo de vida subjetivo e objetivo, permitindo que o entrevistado não conte apenas passagens de sua vida, mas, principalmente, demonstre sua concepção de homem e de mundo.

Augusto Triviños (2008) coloca que a entrevista semi-estruturada é aquela que:

Parte de certos questionamentos básicos, apoiados em teorias e hipóteses, que interessam a pesquisa, e que, em seguida, oferecem amplo campo de interrogativas, fruto de novas hipóteses que vão surgindo à medida que se recebem as respostas dos informantes. Desta maneira, o informante, seguindo espontaneamente a linha de seu pensamento e de suas experiências dentro do foco principal colocado pelo investigador, começa a participar na elaboração do conteúdo da pesquisa (TRIVIÑOS, 2008, p. 146).

Ao propiciar recortes do cotidiano, as entrevistas utilizadas nas Histórias de Vida fazem emergir novos olhares e novas escutas não apenas no pesquisador, mas também no sujeito da pesquisa, que pode vir a repensar sua própria trajetória como ator num contexto social específico, pois as problematizações proporcionadas pelos questionamentos do pesquisador acarretarão reflexões sobre todo o processo e sobre todos os 
envolvidos.

Augusto Triviños (2008, p. 153) conceitua observação como:

Destacar de um conjunto (objetos, pessoas, animais, etc.) algo especificamente, prestando, por exemplo, atenção em suas características (cor, tamanho, etc.). Observar um fenômeno social significa, em primeiro lugar, que determinado evento social, simples ou complexo, tenha sido abstratamente separado de seu contexto para que, em sua dimensão singular, seja estudado em seus atos, atividades, significados, relações, etc. Individualizam-se ou agrupam-se os fenômenos dentro de uma realidade que é indivisível, até captar, se for possível, sua essência numa perspectiva específica e ampla, ao mesmo tempo, de contradições, dinamismos, de relações, etc.

Observar é focalizar-se em determinados aspectos pontuais para os objetivos da pesquisa, procurando centrar não apenas o olhar, mas também o ouvido, o sentimento, nas ações que ocorrem. É procurar captar a essência de determinado fenômeno, articulando-o com o contexto social e cultural em que ocorre.

Alberto Melucci (2005, p. 318) coloca que "cada observação é, por definição, sempre intervenção". Então também foi levado em conta nesse processo o papel participante da pesquisadora no contexto pesquisado e as mobilizações que tal cenário acarretou na mesma, procurando desenvolver uma escrita reflexiva, que utiliza a linguagem para compreender e elucidar a realidade.

As anotações de campo são compreendidas como "todas as observações e reflexões que realizamos sobre expressões verbais e ações dos sujeitos, descrevendo-as, primeiro, e fazendo comentários críticos, em seguida, sobre as mesmas" (TRIVIÑOS, 2008, p. 154).

As anotações no Diário de Campo forneceram o material necessário para a efetivação dos resultados da pesquisa, no momento em que propiciou relembrar não apenas o observado, mas principalmente o que acarretou. Para realizar as descrições do material observado no Diário de Campo tomou-se como referência Juarez Dayrell (1996), professor da Universidade Federal de Minas Gerais e pesquisador sobre temáticas ligadas a juventude, escola e periferia.

De acordo com as concepções de Dayrell (1996), procurou-se realizar uma descrição detalhada das ações dos sujeitos, de maneira a compreender sua cotidianidade e suas relações com seus corpos, sua aprendizagem, seus pares e com o entorno. Os sujeitos são concebidos como atores ativos do processo, capazes de criarem-se e recriarem-se continuamente por meio de suas ações, que também refletem no contexto.

Para participar deste estudo foram escolhidas duas jovens com 15 e 16 anos de idade respectivamente, alunas da ONG Royale Escola de Dança e Integração Social, moradoras de duas das comunidades da zona oeste da cidade de Santa Maria - RS, pertencente às famílias cujas rendas econômicas variam entre dois salários mínimos e expostas a situações de vulnerabilidade social.

Foi realizada uma entrevista aberta com as jovens, englobando aspectos relacionados com suas vidas escolares e pessoais. De acordo com Rosália Duarte (2004, p. 216), a referida entrevista "propiciam situações de contato, ao mesmo tempo formais e informais, de forma a provocar um discurso mais ou menos livre, mas que atenda os objetivos da pesquisa".

Ainda foram observadas as ações das jovens em suas atividades na Royale Escola de Dança e Integração no período de 21/06/2010 a 14/07/2010. As observações foram registradas no Diário de Campo, focando aspectos relacionados às interações sociais das jovens com seus pares.

\section{Terceiro momento: as trajetórias dançantes das bailarinas da Royale}

As jovens em estudo serão identificadas como C. e P.

C. tem 16 anos e seu pai é zelador de uma escola municipal de ensino fundamental na zona oeste da cidade de Santa Maria - RS. Sua mãe é diarista em duas casas de família. C. tem um irmão mais velho que trabalha num supermercado na zona oeste. A renda familiar gira em torno de dois salários mínimos. C. está cursando o $3^{\circ}$ ano do ensino médio em uma escola estadual, no Bairro Centro, no turno da manhã e também frequenta um curso preparatório para o vestibular no turno da noite. C. estuda na Royale Escola de Dança e Integração Social há oito anos e encontra-se na turma de balé de Nível Adiantado, realiza aulas três vezes por semana (segundas, quartas e sextasfeiras), das $18 \mathrm{~h} 15 \mathrm{~min}$ às $19 \mathrm{~h} 45 \mathrm{~min}$.

P. tem 15 anos. Seus pais são separados e a mãe casou novamente com F. Ele é considerado pela jovem como seu verdadeiro pai, pois ela tinha três anos quando ocorreu o novo casamento da mãe. P. não tem nenhum contato com seu pai biológico. 
F. trabalha em uma oficina mecânica e a mãe da menina trabalha como empregada doméstica. P. tem uma irmã menor. A renda familiar gira em torno de dois salários mínimos. A jovem está cursando o $1^{\circ}$ ano do ensino médio em uma escola estadual da região oeste da cidade de Santa Maria - RS. P. frequenta a Royale há seis anos e encontra-se na Turma de balé de Nível Intermediário, realiza aulas duas vezes por semana (terças e quintas-feiras), das $18 \mathrm{~h} 15 \mathrm{~min}$ às $19 \mathrm{~h} 45 \mathrm{~min}$.

As entrevistas foram realizadas na Royale Escola de Dança e Integração Social, mais precisamente na Sala das Oficinas. P. realizou sua entrevista no dia 08/06/2010, com início às $18 \mathrm{~h} 15 \mathrm{~min}$, terminando em torno de $19 \mathrm{~h} 20 \mathrm{~min}$. A entrevista de C. foi realizada no dia 09/06/2010, com início às $18 \mathrm{~h} 30 \mathrm{~min}$, terminando em torno de $19 \mathrm{~h}$.

O primeiro fragmento trazido refere-se, na época, à vida cotidiana das jovens:

Eu acordo às seis da manhã. Daí eu tenho uma hora para me arrumar. Daí às sete eu vou na parada. Daí eu vou na parada de baixo, tem a da faixa e a da faixinha. Daí eu pego na faixinha. Vou pra aula. Começa às sete e meia a aula e vai até meio-dia e dez. Saio e vou para casa. Daí chego em casa, almoço, descanso um pouco e uma e meia, quando precisa, volto para o colégio para estudar em grupo ou fazer trabalho. Volto para casa umas quatro horas. Daí descanso. Quando tem balé venho primeiro para cá e depois para o cursinho. Senão vou só para o cursinho. Saio às dez e meia da noite, vou para casa, chego às onze horas, janto e durmo [...] Sim. Ela (a mãe) trabalha fora. Daí quando eu não tenho que ir de tarde para o colégio eu ajudo: limpo a casa, lavo a louça. (C, 09/06/2010)

Bom, eu acordo, arrumo minha cama e da minha irmã. Cuido dela até meio-dia, aí eu faço almoço, daí a mãe chega, eu passo ela (irmã menor) para mãe, daí eu pego as minhas coisas e vou rapidinho para o colégio. Daí os dias que eu venho para cá (Royale) eu saio mais cedo (da escola). Daí eu venho da aula, já chego atrasada, correndo me arrumo, daí entro (Sala de Dança da Royale) Daí tem o tempo (da aula de balé), eu saio me arrumo, chego em casa morrendo de fome, como, vou tomar banho, daí fico sentada vendo televisão. Daí se tem alguma coisa, tema, eu faço depois que todo mundo vai dormir, daí eu fico sozinha na sala, por que eu não posso fazer nada com minha irmã. Daí depois fico ali e vou dormir. (P, 08/06/2010)
Em relação à cotidianidade, Carlos Eduardo Ferraço (2007) coloca que:

Um primeiro aspecto que temos tentado pensar se coloca na própria condição da vida vivida no cotidiano. Assim, em vez de um sistema formal e a priori de categorias, conceitos, estruturas, classificações, ou outras formas de regulação, de ordenação exterior à vida cotidiana; temos considerado a possibilidade de pensar o cotidiano como redes de fazeressaberes tecidas pelos sujeitos cotidianos (FERRAÇO, 2007, p. 77).

Num primeiro momento, parece que as rotinas descritas pelas jovens são marcadas pela repetição, ou seja, cada dia se constituía na repetição do dia anterior. Mas, quando se apura mais os sentidos, nota-se que a intencionalidade de cada ação tem um significado próprio, de acordo com aquilo que a provocou, criando novos saberes no momento em que o sujeito se relacionou com o outro e com o mundo.

Para C. e P. o próprio ato de frequentar a Royale constituía-se num marco diferencial em relação a outros membros das comunidades em que viviam, dando um novo sentido a suas rotinas e a suas relações consigo mesmas e com o entorno. E foi essa rede de significados construída pelas ações cotidianas que proporcionaram que o sujeito criasse e recriasse constantemente sua história.

Conforme Alberto Melucci (2004), os atores sociais são capazes, por meio da problematização sobre si e sobre seu papel no mundo, de reconhecerem-se como sujeitos individuais, mas também como membros de uma comunidade, tornando seu agir parte integrante do mundo social e cultural, transformando e recriando a realidade.

Em relação ao exposto, é trazido um momento da fala de P., quando estabeleceu diferenças entre seu grupo de amigas da escola regular e da Royale: "Lá na escola (regular) cada uma faz uma coisa e aqui todas tão juntas, unidas por uma mesma coisa. Todas querem fazer a mesma coisa. É um grupo!” (P, 08/06/2010).

P. reconheceu que fazia parte de um contexto cultural específico, ou seja, era uma bailarina da Royale, e se reconheceu como tal, ao construir uma identidade individual. A convivência em um grupo que teve interesses e objetivos em comum propiciou a formação de uma identidade coletiva, em que cada sujeito era capaz de tomar consciência de seu papel como ator social na trama cotidiana da Sala de Dança, do palco e da vida. 
A noção de grupalidade, de identidade coletiva, permitiu a reelaboração e construção de novos significados sobre as experiências vivenciadas e, consequentemente, a recriação de normas e regras de conduta que iriam reger o grupo. Foram as interações entre seus membros (permeadas por afinidades, atritos, negociações, interesses, desejos, etc.) que iriam tecer novas formas de pensar e agir, fortalecendo as relações entre os sujeitos e refletindo no entorno social e cultural.

A identidade coletiva, de acordo com Alberto Melucci (1999), propicia que os atores possam construir ativamente o sentido de suas ações, ao assumir um papel específico de acordo com o cenário. Este age como catalisador da ação e desencadeia comportamentos diferenciados na troca de cada cenografia, num rito de passagem constante de criação e recriação de sensações, emoções e aprendizagens, pois:

Em cada situação, há uma dimensão simbólica, que se expressa nos gestos e posturas acompanhada de sentimentos. Cada um dos seus rituais possui uma dimensão pedagógica, na maioria das vezes implícita, independente da intencionalidade ou dos objetivos explícitos da escola (DAYRELL,1996, p. 150).

\section{Tal fato foi observado na turma de C.:}

Outro fator interessante foi à mudança no comportamento das meninas quando entraram na Sala de Dança. É uma tomada de consciência de seu papel como bailarinas, como pertencentes a um grupo que necessita de um comportamento específico para a obtenção de seus objetivos, nesse caso, concentrar-se para alcançar aprimoramento técnico (Diário de Campo, 23/06/2010).

C. e suas colegas assumiram identidades de "bailarinas do nível adiantado da Royale", ao expressar o comportamento condizente com esse papel. No cenário do vestiário da ONG pode ocorrer uma "grande algazarra de vozes e risos" (Diário de Campo, 21/06/2010), mas a porta da Sala de Dança constituía-se no portal de passagem para outra cenografia, que estabelecia um novo modo de comportamento, adequado à bailarina clássica, que necessitava focar sua atenção no trabalho corporal.

Outro fragmento trazido foi uma resposta de C. quando questionada sobre o que aprendeu na Royale:

Muitas coisas me ensinou. Começou pela educação. Quando eu entrei aqui eu achei que era só dançar. Bom, mas aqui tinha tudo: as oficinas, o boletim (apresentação bimestral do boletim escolar para a pedagoga da Royale), quando tu ia mal no colégio tinha reforço, higiene. Sobre história da dança também tinha que aprender. Aprendi também a conversar melhor, por que eu era muito fechada. Aprendi a dialogar mais com as pessoas. Assim, tudo! A Royale é como o meu segundo lar! (C, 09/06/2010).

P. complementa: "Eu acho que essa coisa de persistir, de não desistir nunca! Aquele ano que eu parei eu vi que eu não me dei bem. Eu podia tá mais avançada (no balé). Aqui também a gente aprende os valores que a gente tem aqui dentro, como a amizade" (P, 08/06/2010).

$\mathrm{O}$ espaço vivencial do palco reflete diretamente na vida cotidiana das jovens. O balé traz consigo a disciplina, a dedicação, a persistência, a postura, os valores necessários não apenas para o pleno desenvolvimento da arte, mas também da própria vida, levando em conta o aluno em "sua totalidade, retomando a questão do aluno como um sujeito sócio-cultural, quando sua cultura, seus sentimentos, seu corpo, são mediadores no processo de ensino e aprendizagem" (DAYRELL, 1996, p. 157).

Ao propiciar o contato com a cultura erudita, ao mesmo tempo em que respeita a diversidade cultural, a Royale possibilita que sejam reelaborados e construídos novos significados. Estes levam a reecriação constante do sujeito na e pela cultura, pois no momento em que o indivíduo se apropria e usufrui dos bens culturais, reflete sobre si mesmo e sobre o seu lugar no mundo, podendo tornar-se protagonista de um processo de inclusão e transformação social, cultural, política e econômica, pois "é na prática que se instalam as condições de transformação do impossível em possível" (MARTINS, 2008, p. 57).

Quebra-se o paradigma do domínio da cultura dominante sobre a cultura dominada e começa a construção de uma cultura cidadã, inclusiva, humanizante, que possibilita relações sociais dialógicas e criativas, prenunciando novas escolhas, novas trajetórias, novas utopias.

$\mathrm{O}$ direito à educação, conforme Jaime Pinsky (2008) está inserido junto aos direitos sociais, garante que os indivíduos possam se apropriar e usufruir das riquezas culturais da humanidade, incluindo-os na sociedade.

$\mathrm{O}$ discurso da cultura dominante sobre o 
papel da escolarização procura excluir as classes populares do processo de ensino e aprendizagem, transforma a educação num instrumento de controle do conhecimento, objetivando garantir a manutenção do seu poder político e econômico.

Para isto, impõe seu poder sobre os dominados, desvaloriza seus saberes e prega que os mesmos são incapazes de elaborarem e usufruírem de saberes dominantes, alienando-os de sua cidadania, pois "a transmissão da cultura é sempre ideológica, na medida em que é seletiva e é própria da conservação de modos peculiares de operar, e portanto serve à manutenção de estruturas definidas de poder" (PAIN, 1985, p. 18).

Ficam de fora desse processo, a intensa e complexa trama de relação estabelecida por cada um, suas histórias de vida, suas formas de lidar com o conhecimento, como a própria contextualização da realidade, estabelecida de maneira a explorar conjuntamente aspectos cognitivos, sociais e psíquicos de professores, alunos e espaço escolar na construção do processo de ensino-aprendizagem.

O aluno aprende quando, de alguma forma, o conhecimento se torna significativo para ele, ou seja, quando estabelece relações substantivas e não arbitrárias entre o que se aprende e o que já conhece. É um processo de construção de significados, mediado por sua percepção sobre a escola, o professor e sua atuação, por suas expectativas, pelos conhecimentos prévios que já possui. A aprendizagem implica, assim, estabelecer um diálogo entre o conhecimento a ser ensinado e a cultura de origem do aluno (DAYRELL, 1996, p. 156).

Ao não tocar significativamente o educando, o conhecimento não tem voz, desmembra-se, fica totalmente desvinculado do corpo do sujeito. E professores e educandos não conseguem encaixar o amplo quebra-cabeça do saber, não o contextualizam, perdendo-se nas peças sem sentido. Origina-se um corpo sem intencionalidade, que articula um discurso catatônico, de mera reprodução.

Alicia Fernández (1994, p. 74) diz que "para que aja aprendizagem, intervém o nível cognitivo e o desejante, além do organismo e do corpo". Ou seja, aprender não se relaciona apenas ao nível cognitivo, engloba o sujeito como um todo, nos quais o psíquico e o organismo também interagem para edificar o conhecimento. Este pensamento da área da educação vai de encontro aos princípios somáticos da dança, que também concebem o sujeito em sua totalidade.

Sabe-se que a escola regular além de não conceber o corpo como construtor ativo de conhecimento, ainda o aprisiona como mero "carregador" alienado do saber, constituindo-o num objeto sem participação, como observado no seguinte diálogo ocorrido entre a turma de C.:

C. chegou por volta das 18 horas e ficou conversando com as colegas no vestiário. Reclamou de dor nas costas devido ao peso da mochila escolar: "Sempre tenho que levar um monte de livros para o colégio. É são todos grossos! Pesa demais!". As colegas comentaram que com elas acontece a mesma coisa e o que é pior, muitas vezes levam livros que nem são utilizados na aula. M., uma das meninas que cursa Matemática na UFSM, comentou que "na universidade é a mesma coisa. Sempre tem algo pesado na pasta". Todas riram, chegando a conclusão, que sempre irão carregar bolsas. (Diário de Campo, 05/07/2010).

Ao contrário do repassado na maioria das escolas regulares, o corpo é um sujeito ativo no processo de aprendizagem, incorpora o saber não apenas por meio de práticas corporais, mas também no desenvolvimento de novas posturas $\mathrm{e}$ comportamentos. O corpo aprende ao andar, ao ver, ao ouvir, ao falar, ao cheirar, ao comer. O corpo aprende por meio da cotidianidade, sensibiliza a si e aos outros, constrói e reconstrói o sujeito e o mundo, por meio das ações do indivíduo sobre o entorno. Aprender, então, constitui-se praticamente em sinônimo de viver.

Em relação aos seus sonhos, as jovens colocam que:

É eu continuar dançando balé e ter um lugar como a Royale. Ter um lugar onde eu possa ensinar o que eu aprendi aqui. Eu quero passar tudo que eu aprendi aqui, desde a educação, tudo para outras pessoas (C, 09/06/2010).

Sei lá ... eu quero fazer tanta coisa! Eu já disse que eu quero fazer vestibular para música, mas também quero fazer artes cênicas. Por que eu gosto muito de atuar e cantar. Ai ... sei lá ... Daí eu também gosto de dançar. Daí eu acho que eu vou ser uma atriz-bailarina-cantora [...] Eu quero fazer artes cênicas primeiro. Daí em segundo a música. Eu gosto dos dois. Por que eu tenho muita facilidade de chorar e todo mundo diz: ela é uma atriz! [...] Quero terminar o curso de balé, mas quero continuar dançando aqui. Se eu parar vou me sentir mal, já me acostumei a dançar. E quero fazer um projeto de teatro e outro de 
música na Royale. Quero ensinar os outros aqui também! (P, 08/06/2010).

As práticas artísticas e educativas realizadas pela Royale Escola de Dança e Integração Social permitiu que as jovens, ao sentirem-se parte do coletivo, construíssem sonhos que colaboraram para a continuidade e aperfeiçoamento desse coletivo. Ou seja, as jovens não pensavam apenas na sua realização individual, mas também em auxiliar outros sujeitos a se descobrirem e desenvolverem suas potencialidades, num processo constante de construção e manutenção da cidadania.

\section{Considerações finais}

A aprendizagem do corpo dentro da proposta da Royale Escola de Dança e Integração está justamente em promover, por meio de uma educação problematizadora, uma via de conhecimento singular de si mesmo e da realidade em que a capacidade de percepção sensível e de reinvenção está fortemente presente, pois "uma das tarefas fundamentais do educador progressista é, sensível à leitura e à releitura do grupo, provocá-lo bem como estimular a generalização da nova forma de compreensão do contexto" (FREIRE, 1996, p.83)

Ao descobrir-se como sujeito livre, crítico, reflexivo, participativo em seu meio social, o indivíduo recobra sua capacidade de sonhar e de planejar seu futuro, e se constitui num ator social, que por meio de sua ação é capaz de transformar e resignificar o real.

A Royale promoveu uma ruptura no cotidiano das jovens. Frequentar a Royale significou a não apenas participar de um projeto social preventivo às situações de risco que existiam nas comunidades (drogas, prostituição, violência, etc.), mas acima de tudo foi fazer parte de um espaço diferencial, na qual a sensibilização do corpo ocasionou a sensibilização da alma e construiu novos modos de ser, saber e agir, que levaram à inclusão social e cultural.

Parece que todo o dia que eu passei na escola, em casa é igual e quando eu chego aqui é tudo diferente. Eu saio do meu mundo. Eu entro aqui no vestiário e é uma coisa. Eu entro ali naquela sala (sala de dança) e tudo muda! É um novo mundo! Toca aquela musiquinha e tudo muda! [...] Eu me sinto outra pessoa [...] Esqueço de tudo! Saio de mim! Lá (na sala de dança) entra outra pessoa. Parece que não é mais eu. Eu me solto [...] Daí, lá (na sala de dança) entra a bailarina que não dá prá ver durante o dia, nos outros tempos do dia. Entra uma pessoa que não dá para ver. Lá ela dança! Quem vê não diz: ela dança. E quando chega ali (na Sala de Dança) ela dança! (P, 08/06/2010).

Antes escondidas na cotidianidade de suas comunidades, surgiram as bailarinas no contexto da Sala de Dança da Royale. Bailarinas que construíram novos sonhos, novas trajetórias. Bailarinas que se modificaram constantemente e atingiram os demais com suas ações no palco, na escola, na família.

A convivência no contexto cultural da Royale propiciou às jovens a construção de uma identidade individual (bailarina da Royale), como também uma identidade coletiva (pertencente à turma do nível $\mathrm{X}$ da Royale). Essa identidade coletiva correspondia a uma identidade maior, que englobava a todas: a do grande grupo de bailarinas pertencentes à Royale Escola de Dança e Integração Social. Ou seja, C. e P. se concebiam como bailarinas, que pertenciam a um grupo de bailarinas da Royale, mas que para além das paredes da Royale tinham uma identidade comum com todas as bailarinas da ONG: pertenciam a Royale Escola de Dança e Integração Social. E as "bailarinas da Royale" desenvolveram regras e normas de conduta próprias que as diferenciam das demais bailarinas clássicas da cidade, como pode ser observado no seguinte fragmento registrado no Diário de Campo:

Como na Turma Adiantada, as meninas demonstraram uma clara mudança em seu comportamento na "passagem" do vestiário para a Sala de Dança. Parecem perceber que a dança exige essa mudança de postura, onde a concentração deve imperar. Percebem que como bailarinas da Royale precisam ter uma nova postura frente à vida, compreendendo a importância de seu comportamento não apenas na Sala de Dança, mas também no vestiário, na rua, na escolar regular, etc. Observou-se o mesmo espírito de solidariedade e companheirismo nas meninas da turma de P., que se concebem como um grupo que deve se auxiliar mutuamente para que todos possam progredir. (Diário de Campo, 24/06/2010).

A noção de grupalidade permitiu que as bailarinas construíssem ativamente o significado de suas ações, compreendendo que cada cenografia exigia um comportamento e uma postura diferenciada. Cada membro do grupo era visto como 


\section{ONG de Santa Maria - RS}

fundamental para sua manutenção, isso ao gerar sentimentos solidários e fraternos em detrimento da competição e do individualismo.

A proposta artístico-educativa da Royale Escola de Dança e Integração Social proporciona o contato com a cultura erudita, mas respeita a diversidade cultural. Isto possibilita a contextualização dos conhecimentos gerados, de maneira que possam ser elaborados e reelaborados conjuntamente por todos os participantes das ações, sem imposição da cultura dominante como verdade absoluta.

Ao conceberem-se como construtores de conhecimentos e saberes os sujeitos se reapossam de sua cidadania, resignificando suas vidas.

Um dos pontos mais interessante levantado nos discursos das jovens foi o desejo de continuidade na Royale, de ensinarem o que aprenderam. Esse processo de multiplicação corresponde à possibilidade de também sensibilizar outros sujeitos, para que possam vir a descobrir a si mesmos e modificar suas realidades, tal como C. e P. estavam modificando as suas.

O processo artístico-educativo desenvolvido pelas educadoras da Royale Escola de Dança e Integração Social, que tem o balé como eixo central, propicia influências nas construções das identidades pessoais e coletivas das educandas participantes do projeto, o que indica possibilidades do desenvolvimento da conscientização de seus papéis como cidadãs.

\section{Referências}

ARAÚJO, O. R; SANTOS, S. M. História Oral: vozes, narrativas e textos. IN: Cadernos de História da Educação, Uberlândia, Edufe, n. 6, 2007, p. 191 $-201$.

BUENO, B. O. et al. Histórias de vida e autobiografias na formação de professores e profissão docente (Brasil, 1998-2003). In: Educação e Pesquisa, São Paulo, v. 32, n. 2, 2006, p. 385-410.

DELORS, J. Educação: um tesouro a descobrir. Tradução: Guilherme João de Freitas Teixeira. Relatório para a UNESCO da Comissão Internacional sobre a Educação para o século XXI. Rio Tinto: Asa, 1996

DAYRELL, J. Múltiplos olhares sobre educação e cultura. Belo Horizonte: Editora UFMG, 1996.

DUARTE, R. 2004. Entrevistas em pesquisa qualitativa. In: Educar. Curitiba, Editora UFPR, n. 24, 2004, p. 213-225.

FERNÁNDEZ, A. A mulher escondida na professora: uma leitura psicopedagógica do ser mulher, da corporeidade e da aprendizagem. Porto Alegre: Artes Médicas, 1994.

FERRAÇO, C. E. Pesquisa com o cotidiano. In: Educação e sociedade. Campinas, Editora da UNICAMP, vol. 28, nº. 98, 2007, p. 73 - 95.

FREIRE, P. Educação como prática da liberdade. Rio de Janeiro: Paz e Terra, 1977.

Paz e Terra, 1996.

Pedagogia da autonomia. São Paulo:

MARTINS, J. S. A aparição do demônio na fábrica: origens sociais do eu dividido no subúrbio operário. São Paulo: Editora 34, 2008.

MELUCCI, A. Acción colectiva, vida cotidiana y democracia. México: Centro de Estúdios Sociológicos, 1999.

. O jogo do eu: a mudança de si em uma sociedade global. São Leopoldo: Ed. Unisinos, 2004.

- Por uma sociologia reflexiva: pesquisa qualitativa e cultura. Rio de Janeiro: Petrópolis, Vozes, 2005.

PAÍN, S. Diagnóstico e tratamento dos problemas de aprendizagem. Porto Alegre: Artes Médicas, 1995.

PAIS, J. M. Máscaras, jovens e escolas do diabo. In: Revista brasileira de educação. São Paulo, vol. 13, $n^{\circ} .37,2008$, p. $7-21$.

PINSKY, J. História da cidadania. São Paulo: Contexto, 2008.

STRAZZACAPPA, M. Educação somática e artes cênicas: princípios e aplicações. Campinas: Papirus, 2012.

SOUZA, E. C. A arte de contar e trocar 
experiências: reflexões teóricos metodológicas sobre histórias de vida em formação. In: Revista Educação em Questão. Natal, v.25, n. 11, 2006. p. 22-39.

TORO, J. B. Códigos da modernidade: capacidades e competências mínimas para participação produtiva no século XIX. 1997. Disponível em <http://www.modusfaciendi.com.br. $>$

TRIVIÑOS, A. Introdução à pesquisa em ciências sociais: a pesquisa qualitativa em educação. São Paulo: Atlas, 2008.

VIANNA, K. A dança. São Paulo: Summus, 2005.

\section{Sobre as autoras}

Daniela Grieco Nascimento e Silva é graduada em Pedagogia pelo Centro Universitário Franciscano (2000), Mestrado em Educação pelo Centro Universitário La Salle (2010), Doutoranda em Educação - Linha de Pesquisa Educação e Artes - na Universidade Federal de Santa Maria (UFSM). Atualmente é diretora artística, coreógrafa e professora de Ballet da ONG Royale Escola de Dança e Integração Social, em Santa Maria - RS.

Silvia Susana Wolff é doutora em Artes pela UNICAMP, graduação/Bacharelado em Comunicação pela Pontifícia Universidade Católica do Rio Grande do Sul (2000) e Mestrado em Artes/Dança pela NEW YORK UNIVERSITY (2005). Atualmente é professora adjunta do Curso de Bacharelado em Dança da Universidade Federal de Santa Maria, atuando como vice-coordenadora do curso de Bacharelado em Dança da UFSM.

Recebido em setembro de 2016.

Aprovado em dezembro de 2016. 